\title{
Polymorphism of the gene eNOS G894T (Glu298Asp) in symptomatic patients with aterosclerosis
}

\author{
F.L. Campedelli ${ }^{1}$, K.S.F. e Silva ${ }^{3}$, D.A. Rodrigues $^{1,2}$, J.V.M. Martins ${ }^{1,2}$, \\ I.R. Costa ${ }^{1,2}$, M.H. Lagares ${ }^{1,2}$, A.M. Barbosa ${ }^{1,2}$, M.P. de Morais ${ }^{1,2}$ and \\ K.K.V.O. Moura ${ }^{1,2}$ \\ ${ }^{1}$ Núcleo de Pesquisa Replicon, Pontifícia Universidade Católica de Goiás, \\ Goiânia, GO, Brasil \\ ${ }^{2}$ Departamento de Biomedicina, Pontifícia Universidade Católica de Goiás, \\ Goiânia, GO, Brasil \\ ${ }^{3}$ Laboratório de Genética e Biologia Molecular, \\ Universidade Federal de Goiás, Goiânia, GO, Brasil \\ Corresponding author: K.S.F. e Silva \\ E-mail: smallbinho@hotmail.com \\ Genet. Mol. Res. 16 (2): gmr16029550 \\ Received November 22, 2016 \\ Accepted March 8, 2017 \\ Published May 4, 2017 \\ DOI http://dx.doi.org/10.4238/gmr16029550
}

Copyright $(2017$ The Authors. This is an open-access article distributed under the terms of the Creative Commons Attribution ShareAlike (CC BY-SA) 4.0 License.

\begin{abstract}
Atherosclerotic and its cardiovascular complications are responsible for 17.5 million deaths a year, according to the World Health Organization. There is consensus that atherosclerosis involves multiple pathogenic processes initiated by endothelial dysfunction, with inflammation and vascular proliferation determining alterations in the matrix, with consequent formation of the atheromatous plaque and its clinical implications. Risk factors such as hypertension, diabetes mellitus, dyslipidemia, and smoking are widely known. Currently, genotyping, which is not directly related to these factors, is not accepted to estimate the risk of cardiovascular diseases, but strong evidence indicates several polymorphic genes as factors of risk and progression
\end{abstract}

Genetics and Molecular Research 16 (2): gmr16029550 
leading to complications of the disease. Among the genes involved, eNOS (endothelial nitric oxide synthase gene), which is responsible for the production of endothelial nitric oxide (an important arterial vasodilator), when presented in polymorphic variation can determine production, malfunction, and predisposition to atherosclerosis. In the present study, we analyzed the G894T polymorphism of the eNOS gene in groups of individuals diagnosed with atherosclerosis and in a control group. We collected 200 blood samples from patients previously diagnosed with atherosclerosis and 100 samples formed the control group. The genotyping analysis for polymorphism of the eNOS gene was determined by PCR. We considered variables such as gender, smoking, smoking history, and alcohol consumption; statistical differences were found in the distribution of case and control groups $(\mathrm{P}=0.0378)$ and in non-smoking patients $(\mathrm{P}=0.0263)$. In the other associations, no statistically significant difference was found. In the population studied, the frequency of the heterozygous genotype (GT) was much higher than in the other populations (GG and TT) in both groups (case and control). The GG genotype showed greater susceptibility to atherosclerosis. Association of the GG genotype in non-smokers also showed greater susceptibility. Gender, alcohol consumption, smoking, and smoking history did not influence atherosclerosis.

Key words: eNOS; Polymorphism; G894T; Atherosclerosis

\section{INTRODUCTION}

The word atheroma was first quoted in studies in 1755 and initially the disease was named arteriosclerosis, or senile arteriosclerosis (Mayerl et al., 2006). A direct relationship between the state of hypercholesterolemia and the deposition of cholesterol inside the arterial wall was proposed in 1924, characterizing plaque formation prone to appear in certain places (Mayerl et al., 2006).

The immuno-inflammatory process is the main initiating factor in the atherogenesis process (Libby, 2012). Several components such as vascular, metabolic and immune system changes are involved in the development of atheroma plaques (Maiure et al., 2013). These changes occur slowly and the inflammatory mechanisms related to the onset of the disease begin even in childhood, when the formation of fatty streaks occurs (Loppnow et al., 2011). Over the years, this aggression to the vascular wall may intensify until it becomes clinically evident (Mayerl et al., 2006). These complications usually occur after 50 years and are related to partial or total obstruction of the vessel. According to the location of obstruction may occur stroke, exacerbation of chronic disease, such as peripheral arterial occlusion, mainly in the lower limbs, acute myocardial infarction, and sudden death (Herrington et al., 2016). Fordiagnostic evaluation of atherosclerotic disease, it is extremely important to carry out a complete anamnesis (Mayerl et al., 2006). In addition, there is a number of factors that influence the onset and evolution of the disease such as age, gender, ethnicity, religion (interference with healthy habits of life), and profession (Cronenwett and Johnstton, 2014). In the presence of complaints or even in the absence of them during general health check-up, it is possible

Genetics and Molecular Research 16 (2): gmr16029550 
to identify elements that indicate the presence of the disease. History of previous vascular diseases and family history of early vascular diseases often justify evaluation of minor and/or major invasiveness diagnostic procedures (Cronenwett and Johnstton, 2014).

Physical examination includes anthropometric assessments such as weight, height, and abdominal circumference; blood pressure measurements, comparative blood pressure between upper limbs (arm-arm index), lower/upper limbs (ankle-brachial index), and pulse palpation. The absence of pulse in any region is a pathognomonic factor of coronary-related diseases (Mayerl et al., 2006). Hyper-pulsatile pressure or pulsatile abdominal mass may indicate the presence of aneurysms, which are related to atherosclerosis, since atheromatosis can lead to both obstruction and dilatation of the arterial wall (Fatini et al., 2005; Cronenwett and Johnstton, 2014).

Diagnostic complementation through examinations is done by laboratory tests to investigate risk factors such as lipid profile (evaluation of total cholesterol and fractions, triglycerides), apolipoprotein dosage, homocysteine levels, glycemic levels, and diabetes mellitus (Fatini et al., 2005).

Atherosclerosis includes coronary disease, ischemic cerebrovascular accident, peripheral chronic obstructive disease, aneurysms, and other complications that are responsible for the main cause of disability and mortality in Brazil and worldwide (Buckley and Ramji, 2015). According to the World Health Organization (2014), cardiovascular diseases account for approximately 17.5 million deaths per year (31\%). In Brazil, the latest data presented by the Brazilian Institute of Geography and Statistics (IBGE), through the Synthesis of Health Indicators, in 2010, with data collection in 2008, show that circulatory diseases have a higher percentage of death in adults (29.5\%), while the second largest cause of deaths, neoplasia, accounts for just $15.6 \%$.

Atherosclerosis is associated with several cofactors that interfere and precipitate its onset and development (Buckley and Ramji, 2015). These factors can be divided into two main categories: unmodifiable and modifiable risk factors (Buckley and Ramji, 2015). Unmodifiable risk factors are related to primary factors and include genetic alterations that predispose people to the disease such as dyslipidemias, systemic arterial hypertension (SAH), diabetes mellitus (DM), hyperhomocysteinemia (HH), and factors inherent to senility such as older age (over 50 years) and gender (male) (Buckley and Ramji, 2015; Herrington et al., 2016).

Incidence, prevalence, morbidity, and increased mortality for males regarding atherosclerosis are well established. This is explained by a complex interaction between genetic, hormonal factors, and exposure to environmental factors that determine risk, as well as the individualized phenotypic of the disease (Idrissi et al., 2016). Several genetic factors are related to the disease, and more than 400 genes have been described in association with atherosclerosis because they are linked to the regulation of endothelial function, inflammation, metabolism of amino acids, lipids, or carbohydrates. The most common ones are CYP1A, GSTs, ApoE, and the nitric oxide synthase (NOS) (Buckley and Ramji, 2015). A large part of these genes related to atherosclerotic disease are polymorphic. They encode proteins involved in the normal physiology of the endothelium and their variations in certain situations may contribute to the molecular etiopathogenesis in cardiovascular diseases (Gaio et al., 2014).

$\mathrm{NO}$ is a small molecule with a weight of $30 \mathrm{D}$. Its production results from the conversion of L-arginine to L-citrulline through the enzymatic activity of the NOS family in endothelial cells. Its production takes place in the vascular wall after stimulation of the agonists, acetylcholine and bradykinin, released during vascular stress by the nitric oxide endothelial synthase isoform (eNOS) (Idrissi et al., 2016).

Genetics and Molecular Research 16 (2): gmr16029550 
Among the genetic factors associated with atherosclerosis, several clinical-genetic studies have identified the polymorphism in the gene encoding $e N O S$ as responsible for the development of atherosclerosis, with varied clinical repercussions (Idrissi et al., 2016). The gene responsible for encoding eNOS is located on the long arm of chromosome 7, region 35 to $36(7 \mathrm{q} 35 \AA 36)$. They present 26 exons and 25 introns, with a total of $21 \mathrm{~kb}$ (Gen Bank D26607), encoded by 4052 nucleotides in the mRNA, and expressed by endothelial cells from both central and peripheral vessels (Gaio et al., 2014).

A few intronic sites have been identified presenting polymorphism and they act differently in the expression of NO within the arterial endothelium (Gaio et al., 2014). An important polymorphism described in the literature is the G894T (a replacement of guanine for a thymine at position 894), or Glu298Asp (a replacement of non-essential amino acid glutamate for the amino acid aspartate at codon 298). This change results in accelerated degradation and significantly reducing $\mathrm{NO}$ production contributing to onset of atherosclerosis (Gaio et al., 2014).

In the process of atherogenesis, interference in risk factors seems to be the pathway for prevention or delay in the evolution of atherosclerotic diseases. Knowledge of the genetic profile may benefit more susceptible individuals with early institution of preventive and drug measures with better prognostic determination and longer survival. In the present paper, we detected the polymorphism of eNOS in patients from Goiânia regarding the SNP G894T and showed the association between the eNOS polymorphism and atherosclerotic disease. We also evaluated the polymorphism related to risk factors such as gender, smoking, and alcohol consumption in case and control groups.

\section{MATERIAL AND METHODS}

We collected peripheral blood samples with heparin from 300 patients for a casecontrol study at the Angiogenesis/Vascular Surgery and Cardiology Department of the Angiogyn Clinic, located in the city of Goiânia. From those, 200 patients had a previous diagnosis of atherosclerotic disease evaluated through clinical history, physical examination, and confirmed by angiography. The other 100 samples formed the control group based on clinical manifestations and non-invasive imaging diagnostic methods.

The inclusion criteria for patients with atherosclerotic disease were age above 38 years, presence of symptoms for atherosclerotic disease (precordial pain, intermittent claudication, resting lower limb pain, and/or ischemic stroke with proven carotid disease), evidence of (coronary, carotid, and/or peripheral angiography), who signed the informed consent form (ICF) and agreed to respond to a survey questionnaire. Exclusion criteria consisted of patients less than 38 years old who did not agree to sign the ICF and/or did not wish to respond to the questionnaire.

For the control group, the inclusion criteria consisted of patients with age above 38 years old and without diagnosis of atherosclerosis disease. They were evaluated by clinical history, physical examination, and/or non-invasive imaging (color Doppler) of carotid arteries, and showing no evidence of atheromatous plaque and without myointimal thickening (myointimal complex $<1 \mathrm{~mm}$ ). They also agreed to sign ICF and to answer the questionnaire. The exclusion criteria were the same for the case group.

The project was approved by the National Committees for Research Ethics and National Information System on Ethics in Research involving Human Subjects CEP/PUC GOIAS (Number 35321614.3.0000.0037).

Genetics and Molecular Research 16 (2): gmr16029550 
We followed the Brazilian Medical Association's Project and Guidelines (2013) in order to evaluate patients regarding smoking. Both the case group and the control group were classified into two distinct groups: smokers, characterized by regular users of tobacco and/ or derivatives and who interrupted the habit of smoking for less than 15 years; non-smokers, characterized by patients who have never used tobacco products and who have interrupted their use for a period longer than 15 years.

In order to perform the extraction of the genomic DNA from the collected blood samples we used the Kaswi kit (Genomic DNAPurification Kit) according to the manufacturer's recommendations at the Replicon Nucleus Research, Laboratory of the Pontifical Catholic University of Goiás. After extraction, DNA was quantified by the NanoVue ${ }^{\mathrm{TM}}$ Plus spectrophotometer, and we only used samples higher than $5 \mathrm{ng} / \mu \mathrm{L}$. The DNA was stored at $-20^{\circ} \mathrm{C}$ until amplified by the polymerase chain reaction (PCR) method in order to verify the eNOS polymorphism. To avoid contamination of the samples, the analysis was performed in an appropriate laminar flow according to the protocol proposed by Frare et al. (2013).

We used three pairs of primers in order to study the eNOS gene polymorphism in G894T: primer forward, normal primer reverse, and mutant primer reverse (Table 1). The presence of the band amplification means that the TT/GT/GG polymorphism is present. PCR was always performed in duplicate. The PCR product was subjected to $2 \%$ agarose gel (Figure 1) electrophoresis in an electric field of $10 \mathrm{~V} / \mathrm{cm}$ and stained with ethidium bromide $(5 \mathrm{mg} /$ $\mathrm{mL}$ ) and then visualized in the $\operatorname{VDS}^{\circledR}$ (Photo Documentation Video System - Amersham Pharmacia Biotech, USA).

We used the Biostat 5.0 software in order to perform the chi-square test and the G-test for the statistical analysis of the eNOS gene polymorphism. Statistical difference was considered significant for $\mathrm{P}<0.05$.

Table 1. Nucleotide sequence of the primers.

\begin{tabular}{l|l|c}
\hline Primers & Sequence & \multicolumn{1}{c}{ Size } \\
\hline \multirow{2}{*}{ eNOS } & F $_{\mathrm{c}}$ 5'-AAGGCAGGAGACAGTGGATG-3' & \multicolumn{1}{c}{$196 \mathrm{bp}$} \\
\cline { 2 - 2 } & RN $_{\mathrm{N}}$ 5'-TGAAGGAAGAGTTCTGGTGGC-3' & \\
\cline { 2 - 2 } & $\mathrm{R}_{\mathrm{M}}$ : 5'-GAAGGAAGAGTTCTGGTGGA-3' & \\
\hline
\end{tabular}

Tajehmiri et al. (2013).

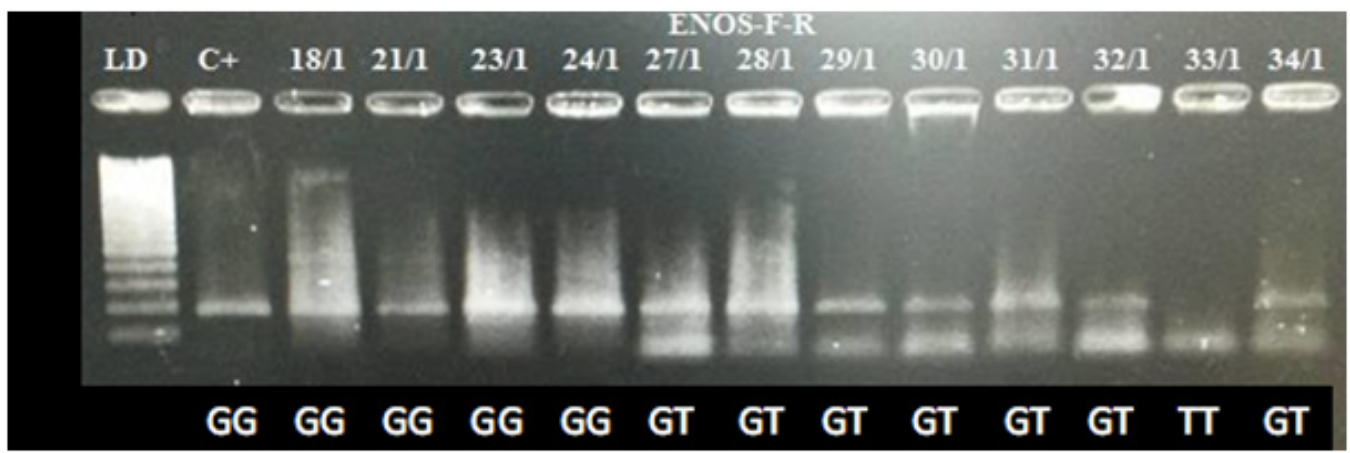

Figure 1. PCR product on $2 \%$ agarose gel stained with ethidium bromide.

Genetics and Molecular Research 16 (2): gmr16029550 


\section{RESULTS}

We analyzed 200 patients with a mean age of 61.1 years old in the case group while in the control group there were 100 patients with the mean age of 50.2 years old.

The G894T polymorphism of the eNOS gene found in the case group was $10 \%$ (20/200) GG, 76\% (152/200) GT, and 14\% (28/200) TT. In the control group, we found $2 \%$ $(2 / 100) \mathrm{GG}, 85 \%(85 / 100) \mathrm{GT}$, and $13 \%(13 / 100) \mathrm{TT}$. We founda statistical difference between the case and control groups regarding the genotypic distribution $(\mathrm{P}=0.0378$; Table 2$)$.

Table 2. Distribution of the eNOS polymorphism gene in the case-control groups.

\begin{tabular}{l|c|c|c|c|c}
\hline & GG $[\mathrm{N}(\%)]$ & GT [N (\%)] & TT [N (\%)] & Total [N (\%)] & P* $^{*}$ \\
\hline Case & $20(10)$ & $152(76)$ & $28(14)$ & $200(100)$ & 0.0378 \\
\hline Control & $2(2)$ & $85(85)$ & $13(13)$ & $100(100)$ & \\
\hline
\end{tabular}

*Chi-square test. The difference between the groups for the GG genotype was 5 times higher for the case group.

The genotypic distribution regarding gender showed that males presented 7.6\% (7/92) GG, $79.3 \%(73 / 92)$ GT, and $13.1 \%(12 / 92)$ TT in the case group. The control group had $1.9 \%$ (1/53) GG, 88.7\% (47/53) GT, and 9.4\% (5/53) TT.

The females in the case group had a genotype frequency of $12.1 \%(13 / 108) \mathrm{GG}, 73.1 \%$ (79/108) GT, and 14.8\% (16/108) TT. The control group showed 2\% (1/47) GG, 81\% (38/47) GT, and $17 \%(8 / 47)$ TT. We did not find statistical significant difference between the genotypes of the G898T polymorphism of the $e N O S$ gene either in males $(\mathrm{P}=0.2133)$ or females $(\mathrm{P}=0.0850$; Table 3$)$.

Table 3. Distribution of the eNOS polymorphism regarding gender in the case and control groups.

\begin{tabular}{l|c|c|c|c|c}
\hline Gender & GG [N (\%)] & GT [N (\%)] & TT [N (\%)] & Total [N (\%)] & P** \\
\hline Male & & & & & \\
\hline Case & $7(7.6)$ & $73(79.3)$ & $12(13.1)$ & $92(100)$ & 0.2133 \\
\hline Control & $1(1.9)$ & $47(88.7)$ & $5(9.4)$ & $53(100)$ & \\
\hline Female & & & & & \\
\hline Case & $13(12.1)$ & $79(73.1)$ & $16(14.8)$ & $108(100)$ & 0.0850 \\
\hline Control & $1(2.0)$ & $38(81.0)$ & $8(17.0)$ & $47(100)$ & \\
\hline
\end{tabular}

**G-test.

We compared the distribution of individuals regarding smoking and found that $35 \%$ (70/199) of patients in the case group and 25.3\% (25/99) in the control group declared to be smokers, whereas $65 \%(129 / 199)$ of individuals in the case group and $74.7 \%(74 / 99)$ in the control group reported not to smoke or discontinuing the habit of smoking for over 15 years.

The association of patients who declared to be smokers in the case group and the frequency of genotypes showed 10\% (7/70) GG, 80\% (56/70) GT, and 10\% (7/70) TT. In the control group, this association presented a frequency of $4 \%(1 / 25) \mathrm{GG}, 88 \%(22 / 25) \mathrm{GT}$, and $8 \%(2 / 25) \mathrm{TT}$, and no statistically significant difference was observed between groups $(\mathrm{P}=0.5658$; Table 4$)$.

Table 4. Association of smoking with eNOS gene genotypes in the case and control groups related to the time of exposure to tobacco.

\begin{tabular}{l|c|c|c|c|c}
\hline \multirow{2}{*}{ Groups } & \multicolumn{3}{|c|}{ Smokers $(<15$ years $)$} & \multirow{2}{*}{ Total } & \\
\cline { 2 - 5 } & GG [N (\%)] & GT [N $(\%)]$ & TT [N $(\%)]$ & & 0.5658 \\
\hline Case & $7(10)$ & $56(80)$ & $7(10)$ & $2(100)$ & $25(100)$ \\
\hline Control & $1(4)$ & $22(88)$ & $2(8)$ & 2 & \\
\hline
\end{tabular}

**G-test.

Genetics and Molecular Research 16 (2): gmr16029550 
In the evaluation of patients who declared themselves non-smokers and patients who declared to have quit smoking for more than 15 years, the frequency found in the case group was $10 \%(13 / 129)$ GG, $73.7 \%$ (95/129), GT and 16.3\% (21/129) TT. In the control group, the frequency of non-smokers and ex-smokers was $1.3 \%(1 / 74) \mathrm{GG}, 83.8 \%(62 / 74) \mathrm{GT}$, and $14.9 \%(11 / 74)$ TT. In this association of genotypes with non-smoker and former smoker over 15 years, we found a statistically significant difference $(\mathrm{P}=0.0263$; Table 5$)$.

Table 5. Association of smoking with eNOS gene genotypes in case and control groups related to the time of
exposure to tobacco.
\begin{tabular}{l|c|c|c|c|c}
\hline & GG [N (\%)] & GT [N (\%)] & TT [N (\%)] & Total & \multirow{2}{*}{$\mathrm{P}^{* *}$} \\
\hline Groups & $13(10)$ & $95(73.7)$ & $21(16.3)$ & $129(100)$ & \multirow{2}{*}{0.0263} \\
\hline Case & $1(1.3)$ & $62(83.8)$ & $11(14.9)$ & $74(100)$ & \\
\hline Control &
\end{tabular}

**G-test.

In the case group the GG genotype was 9 times higher than in the control, indicating a non-association of smoking and the eNOS G894T polymorphism.

We analyzed the relation between quantity of smoking and the eNOS genotypes. In the case group, patients who reported smoking 5 to 10 packs of cigarettes a year had a genotype frequency of $0 \%(0 / 3) \mathrm{GG}, 14 \%(6 / 43) \mathrm{GT}$, and $14.2 \%(1 / 7) \mathrm{TT}$. For patients who smoke from 10 to 20 packs a year, the frequency was $66.7 \%(2 / 3) \mathrm{GG}, 32.5 \%(3 / 7) \mathrm{GT}$, and $42.9 \%$ (3/7) TT. And for individuals who declared smoking 20 or more packs of cigarettes a year, we observed a greater frequency of GT, than GG and TT, both in the case $(53.5 \%)$ and in the control $(23 \%)$ groups. We did not find a statistically significant difference between the case and control groups regarding the quantity of smoking (case group, $\mathrm{P}=0.7302$; control group, $\mathrm{P}=0.0765$; Table 6).

Table 6. Association of smoking with genotypes of the eNOS gene in the case and control groups related to quantity of smoking.

\begin{tabular}{|c|c|c|c|c|}
\hline \multirow[t]{3}{*}{ Packs } & \multicolumn{3}{|c|}{ Smokers } & \multirow[t]{3}{*}{$\mathrm{P}^{* *}$} \\
\hline & \multicolumn{3}{|c|}{ Case group } & \\
\hline & GG [N (\%)] & GT [N (\%)] & TT [N (\%)] & \\
\hline $5-10$ & $0(0.0)$ & $6(14.0)$ & $1(14.2)$ & \multirow[t]{4}{*}{0.7302} \\
\hline $10-20$ & $2(66.7)$ & $14(32.5)$ & $3(42.9)$ & \\
\hline 20 or more & $1(33.3)$ & $23(53.5)$ & $3(42.9)$ & \\
\hline \multirow[t]{3}{*}{ Total } & $3(100.0)$ & $43(100.0)$ & $7(100.0)$ & \\
\hline & \multicolumn{3}{|c|}{ Control group } & \\
\hline & GG [N (\%)] & GT [N (\%)] & TT [N (\%)] & \\
\hline $5-10$ & $1(100.0)$ & $0(0.0)$ & $0(0.0)$ & \multirow[t]{4}{*}{0.0765} \\
\hline $10-20$ & $0(0.0)$ & $10(77.0)$ & $2(100.0)$ & \\
\hline 20 or more & $0(0.0)$ & $3(23.0)$ & $0(0.0)$ & \\
\hline Total & $1(100.0)$ & $13(100.0)$ & $2(100.0)$ & \\
\hline
\end{tabular}

**G-test.

In the analysis of the polymorphism in relation to the consumption of alcoholic beverage, a greater number of individuals declared themselves non-consumers both in the case group (182/200) and in the control group (80/100). The genotype that showed the highest frequency was GT, independently if the patient consumes alcohol or not. For those who consume alcohol the GT frequency was $93.7 \%$ (15/16) in case group and 85\% (17/20) in control group. For the ones who declared not consumers of alcoholic beverage, the GT

Genetics and Molecular Research 16 (2): gmr16029550 
frequency for the case group was $74.1 \%(135 / 182)$ and for the control group $85 \%(68 / 80)$. No statistical difference was observed between the group that consumes alcohol $(\mathrm{P}=0.0734)$ and the group that does not consume alcohol $(\mathrm{P}=0.063$; Table 7).

Table 7. Distribution of eNOS polymorphism in relation to alcohol consumption in the case and control groups.

\begin{tabular}{|c|c|c|c|}
\hline \multirow[t]{2}{*}{ Genotype } & Case [N (\%)] & Control [N (\%)] & \multirow[t]{2}{*}{$\mathrm{P}^{* *}$} \\
\hline & \multicolumn{2}{|c|}{ Consumers } & \\
\hline GG & $1(6.3)$ & $0(0)$ & \multirow[t]{4}{*}{0.0734} \\
\hline GT & $15(93.7)$ & $17(85)$ & \\
\hline TT & $0(0)$ & $3(15)$ & \\
\hline \multirow[t]{2}{*}{ Total } & $16(100.0)$ & $20(100.0)$ & \\
\hline & \multicolumn{2}{|c|}{ Non-consumers } & \\
\hline GG & $19(10.5)$ & $2(2.5)$ & \multirow[t]{4}{*}{0.063} \\
\hline GT & $135(74.1)$ & $68(85)$ & \\
\hline TT & $28(15.4)$ & $10(12.5)$ & \\
\hline Total & $182(100.0)$ & $80(100.0)$ & \\
\hline
\end{tabular}

*Chi-square test. **G-test.

\section{DISCUSSION}

Atherosclerosis is currently responsible for the highest morbidity and mortality rates in the world and in Brazil (IBGE, 2010; Saini et al., 2011; WHO, 2014). Due to the lack of justification for the excessive risk of the disease in situations of precocity of symptoms and their complications, as well as in the absence of traditional risk factors, the study of genetic susceptibility to disease became evident (Mohan et al., 1998).

Since the importance of NO in the regulatory process of vascular homeostasis, and that its levels were regulated by the eNOS gene, several polymorphisms have been studied in an attempt to correlate genetic susceptibility to several cardiovascular diseases (Saini et al., 2011).

The presence of the G894T polymorphism of the eNOS gene in relation to the NO production process is controversial. It is unclear in association studies whether the G894T polymorphism is a functional genetic variant or a marker for another functional variant of this gene or even another adjacent gene (Leeson et al., 2002).

When a case-control study of atherosclerosis is performed, a better definition of the groups is necessary for better interpretation of the results. The recognition of subclinical atherosclerotic disease is still difficult to achieve because it would require more invasive examinations, and as previously stated, lesions may occur at an early age without determining signs and symptoms. The present study sought to select patients with clear symptoms of atherosclerosis in the case group and the complete absence of clinical signs and known risk factors for the disease allied to a non-invasive examination (carotid echo Doppler) to select the control group, in an attempt to reduce bias.

The high degree of miscegenation in the Brazilian population, made up of Europeans, Indians and Africans, determined an important factor of genetic heterogeneity among Brazilians. We could not identify the ancestral roots of the patients studied in both case and control groups, only nationality and region (central-western Brazil). In our study, the presence of a greater number of heterozygous individuals (GT) was evident for both the case (78\%) and the control (85\%) groups. In order to compare the G894T polymorphism of the eNOS gene and cardiac insufficiency, Tardin et al. (2013) studied the population of Rio de Janeiro and he also found a higher genotypic GT frequency (48.3\%) than GG (40\%) and TT (11.7\%).

Genetics and Molecular Research 16 (2): gmr16029550 
In North America, García-González et al. (2015) observed a higher frequency of the GT genotype in patients with a family history of coronary disease in Yucatan, Mexico.

Fatini et al. (2005), in a study of the Caucasian population of central Italy, when evaluating atherosclerotic disease in the carotid artery did not observe a significant difference of genotypic distribution between GT heterozygote individuals and homozygous GG individuals in the group case (43 and $42 \%$, respectively) and in the control group (46 and $44 \%$, respectively) $(\mathrm{P}=0.16)$. A number of other studies in European populations showed an analogous genotypic distribution with a slight predominance for the GG genotype: England (N $=331$, GG 47.8\%, GT 42\%, and TT 10.2\%) (Hingorani et al., 1999). Germany $(\mathrm{N}=190$, GG $50.5 \%$, GT 40\%, and TT 9.5\%) (Krex et al., 2006), Turkey (N = 150, GG 49.3\%, GT 41.3\%, and TT 9.3\%) (Afrasyap and Ozturk, 2004).

Studies in African populations showed a remarkable predominance of the GG genotype. Hillermann et al. (2005), in South Africa, published their results with a small sample $(\mathrm{N}=42)$ showing $78.6 \% \mathrm{GG}, 19 \% \mathrm{GT}$, and $2.4 \% \mathrm{TT}$. Li et al. (2004) showed in their results a genotype frequency of $70.4 \% \mathrm{GG}, 23.9 \% \mathrm{GT}$, and $5.6 \%$ TT in a population of AfricanAmericans.

Gad et al. (2012), in a survey of 104 cases of acute myocardial infarction (AMI) patients and 101 controls, showed a predominance of the GG genotype (58.4\%) in relation to GT (33.7\%) and TT (7.9\%) genotypes.

Regarding studies about Asian populations, it is noteworthy to observe that beyond the predominant GG genotype, there was almost total absence of the TT genotype. Korea (N $=411$, GG 97.6\%, GT 19.5\%, and TT 0.9\%) (Moon et al., 2002), Japan ( $=513$, GG 84.4\%, GT 17.4, and TT 0\%) (Kato et al., 1999), India ( $\mathrm{N}=105$, GG 74.3\%, 25.7\%, and TT $0 \%$ ) (Nishevitha et al., 2009).

According to the literature, several studies present conflicting results regarding the genotypic variation of the G894T polymorphism in the eNOS gene and a greater predisposition to atherosclerosis (Luo et al., 2014). In the population that we studied, it was observed that the presence of the GG genotype showed a greater predisposition to atherosclerosis since there was a statistically significant difference between the case and control groups and the GG genotype was 5 times higher in individuals in the case group than in the control group. No other studies were found in the Brazilian population that correlated the G894T polymorphism with atherosclerosis.

Luo et al. (2014) performed a meta-analysis studying the G894T polymorphism and its relation to AMI and found a significant association in a subgroup of Asians $(\mathrm{P}<0.05)$, but did not find statistical significance in non-Asian groups $(\mathrm{P}>0.05)$. They conclude that ethnicity has a strong relation to the definition in association with G894T X polymorphism and risk of AMI.

Kaur et al. (2015), in their studies with 120 stroke patients and 101 controls, found strong impact of the eNOS G894T polymorphism as a predisposing factor in cerebral ischemic disease in the population of northern India. However, this relationship occurred for the TT genotype $(\mathrm{P}=0.05)$ and the $\mathrm{T}$ allele $(\mathrm{P}=0.014)$. Mokretar et al. $(2016)$ in a cohort study of Bulgarian patients presented a high percentage of T894 alleles in patients with coronary ischemia $(\mathrm{N}=171)$ compared to the control group $(\mathrm{N}=123)(\mathrm{P}=0.006)$.

Antoniades et al. (2005) in their studies with 229 patients who underwent AMI in the early age (before 55 years old) found the TT homozygous polymorphism for G894T with a significant difference, as well as Isordia-Salas et al. (2009) who described Glu298ASP as

Genetics and Molecular Research 16 (2): gmr16029550 
an independent risk factor for early AMI. Spence et al. (2004) described in their studies that homozygous individuals for the TT genotypic mutation had no association with the risk of AMI. Fatini et al. (2005) evaluated Caucasian patients and found no statistical difference for the G894T polymorphism $(\mathrm{P}=0.16)$ as well as Andrikopoulos et al. (2008) who did not find statistical significance of the G894T polymorphism in patients with AMI.

Gender as a risk factor for atherosclerosis has already been widely studied, and it has a strong tendency towards male gender due to genetic, hormonal, and even cultural reasons (Winham, et al., 2015). However, when the relationship between the G894T polymorphism of the eNOS gene between the case and control groups with both male and female genotypes was evaluated in our study, no statistical difference was found. Sinici et al. (2009) investigated G894T polymorphism in the Turkish population and its correlation with vascular disease and also did not find a significant correlation between male and female. Gad et al. (2012) also found no statistical difference between male and female that could contribute to a greater influence on the polymorphism on the Egyptian population. Nasr et al. (2016), in a study of the eNOS G894T polymorphism as a marker of susceptibility to obesity in the Tunisian population, revealed a high frequency of male individuals with the TT genotype compared to the control group, but they did not find a significant association for altered vascular function.

In order to analyze the smoking habit variable, we divided both the case and control groups into two distinct subgroups: smokers, characterized by regular users of tobacco and/ or derivatives and who interrupted the habit of smoking for less than 15 years; non-smokers, characterized by patients who have never used tobacco products and who have interrupted their use for a period longer than 15 years. This classification option was performed because data from Associação Médica Brasileira (2013) describe that the risk of an acute cardiac event is reduced by half after 1 year of smoking cessation and also it is equal to the risk of the nonsmokers whose cessation is longer than 15 years.

Tobacco has more than 4000 chemical components, such as carbon monoxide, carbon dioxide, ammonia, nitrogen oxide, hydrogen cyanide, and nicotine. It is considered an important vasoconstrictor, with direct deleterious action on the arterial wall by oxidative stress, leading to endothelial dysfunction (Dzida et al., 2012). Furthermore, it is associated with the undesired effect of elevation of blood pressure and heart rate. The habit of smoking has been linked as an important risk factor for atherosclerosis. Several studies have shown that the risk is to the number of cigarettes consumed and the duration of the habit (Wenger, 1997; Vogt et al., 1996). However, in our study, when we analyzed the relationship of the G894T polymorphism with the eNOS gene in individuals who declared themselves smokers, as well as regarding the quantity of smoking in both case and control groups, the influence of this risk factor was not evident in the population under study. Idrissi et al. (2016), studying the same G894Tpolymorphism found statistical difference in relation to smoking $(P=0.04)$, but they did not mention the quantity of smoking of the groups.

About the subgroup of patients who stopped smoking for 15 years or longer and patients who never smoked, we observed in this present study statistical relevance for the GG genotype mainly in the group of patients with symptoms for atherosclerosis. Dzida et al. (2012) analyzed 166 Polish individuals who underwent AMI. They showed a higher percentage of non-smokers with the GG genotype (86\%) than the TT + GT genotype (14\%). However, it shows the occurrence of a higher frequency of the T allele for the eNOS G894T polymorphism among smokers than non-smokers $(\mathrm{P}=0.039)$ and concludes that smoking had an impact on the association with the G894T polymorphism.

Genetics and Molecular Research 16 (2): gmr16029550 
The relationship between alcohol consumption as a risk factor of atherosclerosis is controversial. In an Italian population study conducted by Kiechl et al. (1998), they concluded that there are adverse but also beneficial effects of alcohol in relation to the disease or even in its prevention. As a protective factor it could be explained by the sporadic consumption of light drinks (alcohol consumption $<50 \mathrm{~g} / \mathrm{dL}$ ), due to its antithrombotic effects and inhibiting the atherogenic action of high LDL-C levels. The adverse effects would be related to the high consumption of the so-called heavy drinks (alcohol consumption ${ }^{3} 100 \mathrm{~g} / \mathrm{dL}$ ).

Toda and Ayajiki (2010), in a review study, when evaluating the association of NO vascular action and alcohol consumption, observed that NO concentration was inverse to alcohol consumption. That is, low alcohol concentrations determined increased endothelial NO rates by increased activation and NOS expression. On the other hand, the presence of high alcohol concentration or chronic ingestion resulted in impairment of the endothelial function with a significant reduction in NO production.

In the present study, we evaluated the relationship between the case and control groups who reported alcohol consumption and the G894T polymorphism, and the groups that declared they did not consume alcoholic beverage and the same polymorphism. No subdivision was made in relation to the quantity and type of alcohol consumed. However, we observed that in the studied groups, individuals who declared that they did not consume alcoholic beverages were 11.3 times higher in the case group and 4 times higher in the control group.

In conclusion, we found no significant statistical difference regarding the G894T polymorphism and gender, patients who smoke or quantity of smoking and alcohol consumption. On the other hand, our results showed that for those patients who stopped smoking for longer than 15 years or those who have never smoked there was a significant difference regarding the genotype GG. Moreover, the population under study showed a higher frequency of heterozygotes (GT) for case and control groups, which may highlight the heterogeneity of the Brazilian population.

\section{Conflicts of interest}

The authors declare no conflict of interest.

\section{ACKNOWLEDGMENTS}

We would like to thank Pontifícia Universidade Católica de Goiás, Goiânia, Brazil (Replicon/Prope/MGene/FAPEG/CNPq) for contribution and support.

\section{REFERENCES}

Afrasyap L and Ozturk G (2004). NO level and endothelial NO synthase gene polymorphism with coronary artery disease from the Turkish population. Acta Biochim. Biophys. Sin. (Shanghai) 36: 661-666. http://dx.doi.org/10.1093/ abbs $/ 36.10 .661$

Andrikopoulos GK, Grammatopoulos DK, Tzeis SE, Zervou SI, et al.; GEMIG study investigators (2008). Association of the $894 \mathrm{G}>\mathrm{T}$ polymorphism in the endothelial nitric oxide synthase gene with risk of acute myocardial infarction. BMC Med. Genet. 9: 43-49. http://dx.doi.org/10.1186/1471-2350-9-43

Antoniades C, Tousoulis D, Vasiliadou C, Pitsavos C, et al. (2005). Genetic polymorphism on endothelial nitric oxide synthase affects endothelial activation and inflammatory response during the acute phase of myocardial infarction. $J$. Am. Coll. Cardiol. 46: 1101-1109. http://dx.doi.org/10.1016/j.jacc.2005.05.072

Genetics and Molecular Research 16 (2): gmr16029550 
Associação Médica Brasileira (2013). Instituto Nacional de Câncer José Alencar Gomes da Silva; Aliança de Controle do Tabagismo. Fonte: Rio de Janeiro.

Buckley ML and Ramji DP (2015). The influence of dysfunctional signaling and lipid homeostasis in mediating the inflammatory responses during atherosclerosis. Biochim. Biophys. Acta 1852: 1498-1510. http://dx.doi.org/10.1016/j. bbadis.2015.04.011

Cronenwett J and Johnstton K (2014). Rutherford's Vascular Surgery. 8th ed. Elselvier.

Dzida G, Sobstyl J, Puźniak A, Prystupa A, et al. (2012). Impact of smoking status on particular genetic polymorphisms associations with cardiovascular diseases. J. Pre-Clin. Clin. Res. 6: 31-34.

Fatini C, Sofi F, Sticchi E, Bolli P, et al. (2005). eNOS G894T polymorphism as a mild predisposing factor for abdominal aortic aneurysm. J. Vasc. Surg. 42: 415-419. http://dx.doi.org/10.1016/j.jvs.2005.05.044

Frare AB, Barbosa AM, Costa IR, Souza SR, et al. (2013). GSTM1 and GSTT1 polymorphisms in endometriosis in women from Goiás, Brazil. Genet. Mol. Res. 12: 2764-2770. http://dx.doi.org/10.4238/2013.August.2.1

Gad MZ, Abdel Rahman MF, Hashad IM, Abdel-Maksoud SM, et al. (2012). Endothelial nitric oxide synthase (G894T) gene polymorphism in a random sample of the Egyptian population: comparison with myocardial infarction patients. Genet. Test. Mol. Biomarkers 16: 695-700. http://dx.doi.org/10.1089/gtmb.2011.0342

Gaio V, Nunes B, Fernandes A, Mendonça F, et al. (2014). Genetic variation at the CYP2C19 gene associated with metabolic syndrome susceptibility in a South Portuguese population: results from the pilot study of the European Health Examination Survey in Portugal. Diabetol. Metab. Syndr. 6: 23. http://dx.doi.org/10.1186/1758-5996-6-23

García-González I, Solís-Cárdenas AdeJ, Flores-Ocampo JA, Alejos-Mex R, et al. (2015). G894T (NOS3) and G1958A (MTHFD1) gene polymorphisms and risk of ischemic heart disease in Yucatan, Mexico. Clin. Investig. Arterioscler. 27: 64-73.

Herrington W, Lacey B, Sherliker P, Armitage J, et al. (2016). Epidemiology of atherosclerosis and the potential to reduce the global burden of atherothrombotic disease. Circ. Res. 118: 535-546. http://dx.doi.org/10.1161/ CIRCRESAHA.115.307611

Hillermann R, Carelse K and Gebhardt GS (2005). The Glu298Asp variant of the endothelial nitric oxide synthase gene is associated with an increased risk for abruptio placentae in pre-eclampsia. J. Hum. Genet. 50: 415-419. http://dx.doi. org/10.1007/s10038-005-0270-8

Hingorani AD, Liang CF, Fatibene J, Lyon A, et al. (1999). A common variant of the endothelial nitric oxide synthase (Glu298-->Asp) is a major risk factor for coronary artery disease in the UK. Circulation 100: 1515-1520. http:// dx.doi.org/10.1161/01.CIR.100.14.1515

IBGE (2010). Síntese dos indicadores de saúde. Available at [www.ibge.gov.br].

Idrissi HH, Hmimech W, Diakite B, Korchi F, et al. (2016). Association of G894T eNOS, 4G/5G PAI and T1131C APOA5 polymorphisms with susceptibility to myocardial infarction in Morocco. Meta Gene 9: 56-61.

Isordia-Salas I, Leaños-Miranda A, Sainz IM, Reyes-Maldonado E, et al. (2009). Association of the plasminogen activator inhibitor-1 gene $4 \mathrm{G} / 5 \mathrm{G}$ polymorphism with ST elevation acute myocardial infarction in young patients. Rev. Esp. Cardiol. 62: 365-372. http://dx.doi.org/10.1016/S0300-8932(09)70893-0

Kaur K, Uppal A and Kaur A (2015). An exonic G894T variant of endothelial nitric oxide synthase gene as a risk factor for ischemic stroke in North Indians. Acta Neurobiol. Exp. (Warsz.) 75: 339-350.

Kato N, Sugiyama T, Morita H, Nabika T, et al. (1999). Lack of evidence for association between the endothelial nitric oxide synthase gene and hypertension. Hypertension 33: 933-936. http://dx.doi.org/10.1161/01.HYP.33.4.933

Kiechl S, Willeit J, Rungger G, Egger G, et al. (1998). Alcohol consumption and atherosclerosis: what is the relation? Prospective results from the Bruneck Study. Stroke 29: 900-907. http://dx.doi.org/10.1161/01.STR.29.5.900

Krex D, Fortun S, Kuhlisch E, Schackert HK, et al. (2006). The role of endothelial nitric oxide synthase (eNOS) genetic variants in European patients with intracranial aneurysms. J. Cereb. Blood Flow Metab. 26: 1250-1255. http://dx.doi. org $/ 10.1038 / \mathrm{sj} . j \mathrm{cbfm} .9600284$

Libby P (2012). Inflammation in atherosclerosis. Arterioscler. Thromb. Vasc. Biol. 32: 2045-2051. http://dx.doi. org/10.1161/ATVBAHA.108.179705

Leeson CP, Hingorani AD, Mullen MJ, Jeerooburkhan N, et al. (2002). Glu298Asp endothelial nitric oxide synthase gene polymorphism interacts with environmental and dietary factors to influence endothelial function. Circ. Res. 90: 11531158. http://dx.doi.org/10.1161/01.RES.0000020562.07492.D4

Li R, Lyn D, Lapu-Bula R, Oduwole A, et al. (2004). Relation of endothelial nitric oxide synthase gene to plasma nitric oxide level, endothelial function, and blood pressure in African Americans. Am. J. Hypertens. 17: 560-567. http:// dx.doi.org/10.1016/j.amjhyper.2004.02.013

Loppnow H, Buerke M, Werdan K and Rose-John S (2011). Contribution of vascular cell-derived cytokines to innate and inflammatory pathways in atherogenesis. J. Cell. Mol. Med. 15: 484-500. http://dx.doi.org/10.1111/j.15824934.2010.01245.x

Genetics and Molecular Research 16 (2): gmr16029550 
Luo J, Wen J, Zhou H, Chen X, et al. (2014). Endothelial nitric oxide synthase gene G894T polymorphism and myocardial infarction: A meta-analysis of 34 studies involving 21068 subjects. Miao X, ed. PLoS One 9: e87196.

Maiure M, Grassia G, Platt A, Carnuccio R, et al. (2013). "Macrophage Autophagy in Atherosclerosis", Hindaw Publishing Corporation, Article ID 584715,14.

Mayerl C, Lukasser M, Sedivy R, Niederegger H, et al. (2006). Atherosclerosis research from past to present - on the track of two pathologists with opposing views, Carl von Rokitansky and Rudolf Virchow. Virchows Arch. 449: 96-103. http://dx.doi.org/10.1007/s00428-006-0176-7

Mohan V, Deepa R, Haranath SP, Premalatha G, et al. (1998). Lipoprotein(a) is an independent risk factor for coronary artery disease in NIDDM patients in South India. Diabetes Care 21: 1819-1823. http://dx.doi.org/10.2337/ diacare.21.11.1819

Mokretar K, Velinov H, Postadzhiyan A and Apostolova M (2016). Association of polymorphisms in endothelial nitric oxide synthesis and renin-angiotensin-aldosterone system with developing of coronary artery disease in bulgarian patients. Genet. Test. Mol. Biomarkers 20: 67-73. http://dx.doi.org/10.1089/gtmb.2015.0195

Moon J, Yoon S, Kim E, Shin C, et al. (2002). Lack of evidence for contribution of Glu298Asp (G894T) polymorphism of endothelial nitric oxide synthase gene to plasma nitric oxide levels. Thromb Res. 107: 129-134.

Nasr HB, Dimassi S, M'hadhbi R, Debbabi H, et al. (2016). Functional G894T (rs1799983) polymorphism and intron-4 VNTR variant of nitric oxide synthase (NOS3) gene are susceptibility biomarkers of obesity among Tunisians. Obes. Res. Clin. Pract. 10: 465-475. http://dx.doi.org/10.1016/j.orcp.2015.04.008

Nishevitha NS, Angeline T and Jeyaraj N (2009). Endothelial nitric oxide synthase (eNOS) Glu298-->Asp polymorphism (G894T) among south Indians. Indian J. Med. Res. 129: 68-71.

Saini V, Bhatnagar MK and Bhattacharjee J (2011). Association of endothelial dysfunction with endothelin, nitric oxide and eNOS Glu298Asp gene polymorphism in coronary artery disease. Dis. Markers 31: 215-222. http://dx.doi. org $/ 10.1155 / 2011 / 419708$

Sinici I, Karahan S and Atalar E (2009). Distribution of endothelial nitric oxide synthase gene polymorphisms in Turkish population. J. Investig. Med. 57: 769-776.

Spence MS, McGlinchey PG, Patterson CC, Allen AR, et al. (2004). Endothelial nitric oxide synthase gene polymorphism and ischemic heart disease. Am. Heart J. 148: 847-851. http://dx.doi.org/10.1016/j.ahj.2004.05.019

Tajehmiri A, Sadeghi H, Mehmandousti S, Kaveh N, et al. (2013). Association of the G894T polymorphism of the endothelial nitric oxide synthase gene with migraine: an Iranian case-control study. Journal of Biology and today's world. 2: 417-424.

Tardin O, Pereira S, Velloso M, Balieiro H, et al. (2013). Polimorfismo G894T da óxido nítrico-sintetase endotelial e o prognóstico na insuficiência cardíaca. Arq. Bras. Cardiol. 101: 352-358.

Toda N and Ayajiki K (2010). Vascular actions of nitric oxide as affected by exposure to alcohol. Alcohol Alcohol. 45: 347-355. http://dx.doi.org/10.1093/alcalc/agq028

Vogt MT, Cauley JA, Scott JC, Kuller LH, et al. (1996). Smoking and mortality among older women: the study of osteoporotic fractures. Arch. Intern. Med. 156: 630-636. http://dx.doi.org/10.1001/archinte.1996.00440060050006

Wenger NK (1997). Preventive cardiology in the elderly. Curr. Opin. Cardiol. 12: 195-201. http://dx.doi. org/10.1097/00001573-199703000-00017

Winham SJ, de Andrade M and Miller VM (2015). Genetics of cardiovascular disease: Importance of sex and ethnicity. Atherosclerosis 241: 219-228. http://dx.doi.org/10.1016/j.atherosclerosis.2015.03.021

World Health Organization (2014). Cardiovascular diseases (CVDs) (Fact sheet No. 312). Available at [http://www.who. int/mediacentre/factsheets/fs317/en/].

Genetics and Molecular Research 16 (2): gmr16029550 